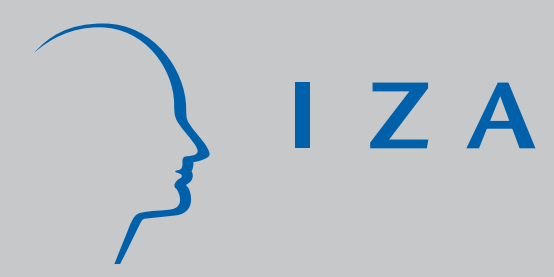

IZADP No. 1559

To Draft or Not to Draft?

Efficiency, Generational Incidence, and Political Economy of Military Conscription

Panu Poutvaara

Andreas Wagener

April 2005 


\title{
To Draft or Not to Draft? Efficiency, Generational Incidence, and Political Economy of Military Conscription
}

\author{
Panu Poutvaara \\ CEBR, Copenhagen Business School, \\ CESifo and IZA Bonn \\ Andreas Wagener \\ University of Vienna, CESifo and CEBR \\ Discussion Paper No. 1559 \\ April 2005
}

IZA

P.O. Box 7240

53072 Bonn

Germany

Phone: +49-228-3894-0

Fax: +49-228-3894-180

Email: iza@iza.org

Any opinions expressed here are those of the author(s) and not those of the institute. Research disseminated by IZA may include views on policy, but the institute itself takes no institutional policy positions.

The Institute for the Study of Labor (IZA) in Bonn is a local and virtual international research center and a place of communication between science, politics and business. IZA is an independent nonprofit company supported by Deutsche Post World Net. The center is associated with the University of Bonn and offers a stimulating research environment through its research networks, research support, and visitors and doctoral programs. IZA engages in (i) original and internationally competitive research in all fields of labor economics, (ii) development of policy concepts, and (iii) dissemination of research results and concepts to the interested public.

IZA Discussion Papers often represent preliminary work and are circulated to encourage discussion. Citation of such a paper should account for its provisional character. A revised version may be available directly from the author. 
IZA Discussion Paper No. 1559

April 2005

\section{ABSTRACT}

\section{To Draft or Not to Draft? Efficiency, Generational Incidence, and Political Economy of Military Conscription}

We study the efficiency and distributional consequences of establishing and abolishing the draft in a dynamic model with overlapping generations, taking into account endogenous human capital formation as well as government budget constraints. The introduction of the draft initially benefits the older generation while harming the young and all future generations. Its Pareto-improving abolition requires levying age-dependent taxes on the young. These being infeasible, abolition of the draft would harm the old. The intergenerational incidence of the gains and losses from its introduction and abolition helps to explain the political allure of the draft.

JEL Classification: H20, H57, I21, D63

Keywords: draft, conscription, education, intergenerational fairness

Corresponding author:

Panu Poutvaara

Centre for Economic and Business Research (CEBR)

Copenhagen Business School

Porcelaenshaven, Bldg 65

DK-2000 Frederiksberg

Denmark

Email: panu.poutvaara@cebr.dk 


\section{Introduction}

Governments can recruit their manpower either by hiring workers at market wages or by compulsory labor service. Both methods rely on the government's power to tax: either as an in-kind tax levied on drafted people in form of forced labor or as monetary taxes, raised to be spent on hired workers' remuneration. Today's democracies no longer rely on forced labor - with the notable exception of the military draft and its corollary, civil service. ${ }^{1}$ Ten out of the 26 NATO members are still utilizing conscription, among them Germany, Turkey, Greece and the Baltic States.

The draft still heavily intrudes into the lives of young men in several Asian countries with spells of at least two years, in Russia and most other successor states of the defunct Soviet Union as well as throughout Latin America, the Arab World and the Middle East (where draft duration is generally between 24 and 36 months). ${ }^{2}$ Israel, Eritrea and Tunisia deserve mention as, unlike the rest of the world, they also draw women into compulsory military service.

Even though most OECD countries have either abolished the military

\footnotetext{
${ }^{1}$ According to ILO (2001), there are three types of forced labor which involve government coercion - as contrasted to slavery, bonded labor, people trafficking etc. which rely on private coercion: (i) compulsory labor, when people are required by law to work on public construction projects; as is practiced in Cambodia, the Central African Republic, Kenya, Burma (Myanmar), Sierra Leone, Swaziland, Tanzania, and Vietnam; (ii) military work, when civilians are forced by the government authorities to work for military purposes; as is widespread in Burma (Myanmar); (iii) prison labor, i.e., the contracting out of prison labor or the forcing of prisoners to work for profit-making enterprises; as is practised in China, Cote d'Ivoire, Madagascar, and Malaysia, but also in democratic countries such as Australia, Austria, France, Germany, New Zealand, and the United States.

${ }^{2}$ In North Korea, compulsory military service takes three to ten years, in South Korea 26-30 months, and in China and Taiwan 24 months. For a comprehensive listing of military systems throughout the world, see CIA (2005).
} 
draft or are debating this, the possibility of re-introducing or maintaining the draft or more general compulsory labor service resurfaces, from time to time. In 2004, the United States issued stop-loss orders that kept thousands of reservists and National Guard members past their agreed terms in Iraq; several critics of President Bush argue that this amounts to a back-door draft. Faced with surging costs for health and long-term care, politicians in ageing Europe sometimes call for introducing a universal social service. ${ }^{3}$

At least since Adam Smith, economists have raised strong reservations concerning the draft and other forms of involuntary service (for recent surveys, see Sandler and Hartley, 1995, Chapter 6; Warner and Asch, 2001). Most obviously, relying on forced labor foregoes the benefits of specialization, as well as fails to take into account differences in opportunity costs and comparative advantage. Staffing military or hospitals by unmotivated or underpaid draftees easily results in shirking and considerable loss of potential output. In countries like Russia, the army is plagued by a culture of violence against draftees, resulting even according to official reports in hundreds of deaths annually (BBC News, 2004). Less drastically, but still testifying of significant costs of military draft, former conscripts usually suffer from lower earnings than those exempted from the draft (see Angrist, 1990, and Imbens and van der Klaauw, 1995). To the extent that these earnings reductions are due to a lower stock of human capital of ex-draftees, they constitute a sizable dynamic cost of the draft that will hit society as a whole - not just draftees (Lau et al., 2004).

Even if there were a consensus that the draft is an inefficient system,

\footnotetext{
${ }^{3}$ In early 2004, several state premiers in Germany argued, across party lines and supported by some church officials, for replacing the traditional German draft scheme with a "compulsory social year". See dw-world.de (2004).
} 
still a considerable opposition might resist its abolition. Older cohorts who have been subject to a draft, understandably, raise an objection that they would be subject to a double burden in case of moving to voluntary forces: they would have to pay for the military service twice, first as young draftees and then later in form of higher taxes to finance a professional army. In a democracy in which the majority of citizens have already passed the age of a draft (which typically is in the late teens and early twenties) and where future generations are not represented, a majority of voters might well support a draft even if it is inefficient from the perspective of steady-state generations. Correspondingly, middle-aged taxpayers might be tempted to introduce a draft system in order to escape the monetary tax burden of paying for a professional army, thereby neglecting dynamic costs that a draft imposes on future generations.

In this paper, we consider the economic and political dynamics of establishing and abolishing compulsory labor services. These compulsory labor services may consist not only of a draft, but also on work in the social sector or other activities deemed socially valuable. For the sake of simplicity we stick to the military terminology though. In short, we show that setting up a draft system (rather than running an all-volunteer army) distorts the accumulation of human capital, and forces young people to work when they should still be studying. Due to this inefficient timing of work and studies, the draft imposes a larger tax burden than collecting the same resources with distorting wage taxes. Therefore, the draft comes at the cost of a lower steady-state stock of human capital.

If a draft has been established, it can always be abolished in a Paretoimproving manner by replacing it with age-dependent taxes, collected only from the young. With a positive interest rate, such frontloading of the tax 
burden results in a lower utility for steady-state generations than if taxes to finance a professional army would be collected from all age cohorts. Thus, it is impossible to fully undo the dynamic costs of once established draft systems again, without additionally hurting at least one generation.

Previous literature on the economic effects of the draft has largely used static and partial equilibrium models. In pioneering studies, Hansen and Weisbrod (1967) and Oi (1967) evaluate the distributive and allocative effects of the draft. They particularly highlight that the draft imposes special inkind taxes and, due to low payment, implicit income taxes exclusively on the young adult part of the population. Unlike the present paper, these papers do not analyze the generational incidence of starting or ending a draft scheme. Taking as their starting point the U.S. draft scheme during the Vietnam War period, Hansen and Weisbrod (1967) as well as Fisher (1969) assess the cost of replacing compulsory conscription by an all-volunteer force. Both studies estimate substantial increases in budgetary needs in order to finance such a transition, but they do not embed this observation into a general equilibrium model with a government budget constraint, alternative ways of tax finance, and the repercussions of this on the rest of the economy. Our paper analyzes the effects of starting and ending the draft when the wage tax rate is determined endogenously to balance the government budget constraint.

Harford and Marcus (1988) and Lee and McKenzie (1992) study the effects of the draft in a static general equilibrium framework with exogenous productivities. In a dynamic general equilibrium model with human capital accumulation, Lau et al. (2004) derive estimates for the excess burden of the draft that results from its distorting effect on human capital decisions. The analysis is confined to comparing the steady states of economies with and 
without the draft. Unlike our paper, none of the studies so far has explicitly taken into account the effects of introducing or abolishing the draft on transition generations.

Modes of recruiting military manpower not only differ in their opportunity costs but also in the direct costs of their administration and implementation. These costs are lower in countries with a well-developed and sophisticated administrative system. Mulligan and Shleifer (2005) offer this as an alternative explanation why some countries adopt a draft system while others do not; they find that countries with an administrative and legal system of French origin are more likely to draft than common law countries. Mulligan and Shleifer (2005) assume that each different conscription system (including the all-volunteer army) is the most efficient solution with some combination of the size of the military force and population. By contrast, we suggest that even if a draft system would be universally less efficient than a voluntary army, it might still be maintained as a political equilibrium due to the intergenerational incidence of tax burden.

Our paper is organized as follows. We introduce an overlapping generations model with a given public sector resource requirement and private investment in education in section 2 . We derive steady states with and without a draft in section 3, and study transition in section 4 . Section 5 concludes.

\section{Model}

Consider an economy with two active overlapping generations. Every generation consists of the same number of ex-ante identical individuals; this number is normalized to one. If necessary, we index time by $t$. We refer to the generation that is in their youth in period $t$ as "generation $t$ ". 
In each of the two periods of his life, every individual has available a certain time endowment, again normalized to one. During youth a fraction $\alpha$ of the time endowment has to be spent for education. Moreover, the young may be called for service, lasting a fraction $d$ of their time endowment. The rest of the time is used for working and denoted by $\ell$. During working age, individuals work full-time.

Individuals are born with some innate human capital, the stock of which is normalized to unity. During their education period, individuals decide on how much effort to spend on studying or training. Effort in studying increases the productivity of human capital according to a function $w=w(e)$. This function is strictly increasing, strictly concave, and satisfies $w(0)=1$. Once acquired, the quality of human capital does not change over the life-cycle.

Effort in education generates a utility cost which in terms of consumption equals $c(e)$; the function $c$ is strictly increasing and convex.

There are two sectors in the economy: a private one and the military. The military is run by the government, and doing this is the only task of the government. We measure output of the military in terms of private consumption and assume that its level is exogenously fixed at $\bar{m}>0$. We, thus, do not analyze the politically or economically optimal size of military expenditure but rather suppose that society considers $\bar{m}$ as a suitable level of national defence and security.

Output $y$ in the private sector is produced by employing labor (measured in efficiency units) in a linear production technology. Thus, for output in period $t$ we obtain:

$$
y_{t}=\ell_{t} \cdot w\left(e_{t}\right)+1 \cdot w\left(e_{t-1}\right)
$$

where $\ell_{t}$ and 1 are the working hours of generation $t$ and $t-1$ in period $t$.

To produce $\bar{m}$, the government can choose between a draft system and a 
professional army (all-volunteer force). ${ }^{4}$ In a draft system, the government recruits a certain number of young individuals before these start their education and employs them in the production of military output for a certain amount of time $d$. Since the productivity of uneducated young is normalized to unity, the length of the draft necessary to produce output $\bar{m}$ is $d=\bar{m}$. As running the military is the only purpose of the government and there are no resources other than human labor needed to operate the military, there is no need to set up a government budget constraint under this regime.

In a professional army, the government buys from the labor market the number of labor units that is necessary to produce $\bar{m}$. It finances military expenditure with a tax on income (private-sector output). Denoting the tax rate in period $t$ by $\tau_{t}$, government budget balance requires

$$
\tau_{t} y_{t}=\bar{m}
$$

We assume that the economy is a small and open one and that there are perfect capital markets where consumption can be shifted over time at an exogenous interest rate of $r \geq 0$ per period.

We assume that individual's preferences are separable in effort for studying and consumption over the two periods of life. Given perfect capital markets, individuals are only interested in the net present value of income over their life-cycle.

In case of a professional army, the net-present value of individual income

\footnotetext{
${ }^{4}$ In reality, armies that only rely on draftees do not exist. All countries employ some professional soldiers to run their armies (and some professional nurses to staff hospitals and care units). Incorporating this aspect into our model could be done at the cost of some additional complexity. However, none of our results would be qualitatively affected by such a modification.
} 
is

$$
w\left(e_{t}\right) \cdot\left[\left(1-\tau_{t}\right)(1-\alpha)+\frac{\left(1-\tau_{t+1}\right)}{1+r}\right]
$$

where $w\left(e_{t}\right)$ is the individual's wage rate and productivity, $1-\alpha$ is working time during youth, and $1 /(1+r)$ is the present value of an additional unit of income during working age (recall that working time is one then). If the tax rate does not change over the life-cycle $\left(\tau_{t+1}=\tau_{t}\right)$, we can write life-time income as

$$
\left(1-\tau_{t}\right) \cdot w\left(e_{t}\right) \cdot \Gamma
$$

where

$$
\Gamma=\frac{2-\alpha-\alpha r+r}{1+r} \leq 2-\alpha
$$

for all $r \geq 0$ and $0 \leq \alpha \leq 1$. Lifetime utility with a professional army then amounts to

$$
u^{p}\left(e_{t}\right)=-c\left(e_{t}\right)+\left(1-\tau_{t}\right) \cdot w\left(e_{t}\right) \cdot \Gamma .
$$

In case of a draft system, individual's time spent for work during youth is $1-\alpha-d$. Provided that (the young expect that) the draft will be maintained also in the next period and, hence, no wage taxes are collected, lifetime income equals

$$
w\left(e_{t}\right) \cdot\left[(1-d-\alpha)+\frac{1}{1+r}\right]=w\left(e_{t}\right) \cdot(\Gamma-d) .
$$

Utility then equals

$$
u^{d}\left(e_{t}\right)=-c\left(e_{t}\right)+w\left(e_{t}\right) \cdot(\Gamma-d) .
$$

\section{Steady States}

We now compare the steady-state equilibria of economies with a professional army and a draft system. Given that variables are time-invariant, we can omit time subscripts. 
In an economy with a professional army, individuals choose $e$ as to maximize (3), thereby taking the tax rate as given. The first-order condition reads as

$$
-c^{\prime}(e)+(1-\tau) \Gamma w^{\prime}(e)=0
$$

and defines optimal education effort as a function of the tax rate. Obviously from (5), the higher taxes the lower educational effort (both $-c(e)$ and $w(e)$ are concave).

Steady-state national income with a professional army is

$$
y(e)=(2-\alpha) \cdot w(e) .
$$

In an equilibrium the tax rate $\tau$ has to be adjusted as to balance government budget; i.e., from (1) and (6),

$$
\tau=\frac{\bar{m}}{(2-\alpha) w(e)} .
$$

The amount of educational investment $e^{p}$ in an economy with a professional army can therefore be determined from plugging (7) into (5); it is implicitly given by:

$$
-c^{\prime}\left(e^{p}\right)+w^{\prime}\left(e^{p}\right) \cdot \frac{(2-\alpha) w\left(e^{p}\right)-\bar{m}}{(2-\alpha) w\left(e^{p}\right)} \cdot \Gamma=0 .
$$

Denote by $V^{p}$ the steady-state utility arising from individual optimization in an economy with a professional army:

$$
V^{p}=u^{p}\left(e^{p}\right)=-c\left(e^{p}\right)+\left(1-\tau^{p}\right) w\left(e^{p}\right)
$$

where $\tau^{p}=\frac{\bar{m}}{(2-\alpha) w\left(e^{p}\right)}$.

With a draft system, the optimal effort invested in human capital $e^{d}$ is determined from maximizing (4); the first-order condition reads as

$$
-c^{\prime}\left(e^{d}\right)+w^{\prime}\left(e^{d}\right) \cdot(\Gamma-\bar{m})=0
$$


where we already substituted $\bar{m}$ for $d$. Denote by $V^{d}$ the maximum utility obtainable in a draft economy:

$$
V^{d}=u^{d}\left(e^{d}\right)=-c\left(e^{d}\right)+w\left(e^{d}\right)(\Gamma-\bar{m}) .
$$

A comparison of a drafted and a professional army yields the following results:

Proposition 1 For all levels of military output $\bar{m}$, the effort into human capital and, therefore, national output and private consumption are lower in an economy with a draft system than in an economy with a professional army:

$$
e^{d}<e^{p}
$$

Proof: Denote the function on the RHS of $(9)$ by $\phi(e)$. Observe that $\phi$ is strictly decreasing in $e$ and $\phi\left(e^{d}\right)=0$. Evaluate $\phi$ for $e=e^{p}$ and replace $-c^{\prime}\left(e^{p}\right)$ from $(8)$ :

$$
\begin{aligned}
\phi\left(e^{p}\right) & =-c^{\prime}\left(e^{p}\right)+w^{\prime}\left(e^{p}\right) \cdot(\Gamma-\bar{m}) \\
& =w^{\prime}\left(e^{p}\right) \cdot\left[\Gamma-\bar{m}-\Gamma \cdot \frac{(2-\alpha) w\left(e^{p}\right)-\bar{m}}{(2-\alpha) w\left(e^{p}\right)}\right] .
\end{aligned}
$$

The square-bracketed expression is negative if and only if

$$
w\left(e^{p}\right)>\frac{\Gamma}{2-\alpha} .
$$

This condition always holds due to (2) and $w(e)$ being increasing in $e$ and therefore $w\left(e^{p}\right)>w(0)=1$. We, thus, have $\phi\left(e^{p}\right)<0=\phi\left(e^{d}\right)$ and the claim $e^{d}<e^{p}$ follows from the strict monotonicity of $\phi$.

As productivity increases in $e$ and the government always takes away the same absolute amount $\bar{m}$ of resources for the military, the assertions for output and consumption follow immediately. 
Proposition 1 shows that a draft system distorts the accumulation of human capital, relative to a professional army. Empirical evidence for this dynamic cost of the draft has been found by Angrist (1990) and Imbens and van der Klaauw (1995), and computational estimates for its considerable impact on national output are provided in Lau et al. (2004).

Proposition 2 The utility level in an economy with a draft system always falls short of the utility level in an economy with a professional army:

$$
V^{d}<V^{p}
$$

Proof: Denote by $\tau^{p}$ the equilibrium tax rate in an economy with a professional army. Then the following inequalities hold:

$$
\begin{aligned}
V^{p} & =-c\left(e^{p}\right)+\left(1-\tau^{p}\right) w\left(e^{p}\right) \Gamma \\
& \geq-c\left(e^{d}\right)+\left(1-\tau^{p}\right) w\left(e^{d}\right) \Gamma \\
& =-c\left(e^{d}\right)+w\left(e^{d}\right) \Gamma-\frac{\bar{m}}{(2-\alpha) w\left(e^{p}\right)} w\left(e^{d}\right) \Gamma \\
& >-c\left(e^{d}\right)+w\left(e^{d}\right)(\Gamma-\bar{m})=V^{d} .
\end{aligned}
$$

The second line is by a revealed-preference argument, the third replaces the budget-balancing tax rate $\tau^{p}$, and the fourth follows from (10).

Proposition 2 establishes the superiority of a professional army over a drafted army in terms of steady-state utilities. It adds to a collection of results in the literature that the draft is an economically suboptimal arrangement for recruiting staff to the government sector (for a survey see, e.g., Sandler and Hartley, 1995, Chapter 6). However, these findings are based on static inefficiencies (forgone benefits of specialization, inefficient job matches etc.). By contrast, Proposition 2 emerges from the intertemporal distortion of human capital investments identified in Proposition 1. 


\section{Transition Dynamics}

\subsection{Introducing the draft}

Suppose that prior to some date $t$ the economy was running a professional army, but that the government announces plans to introduce a draft system effectively of date $t$, before generation $t$ will decide on their study effort. We assume that this policy change could not be anticipated before period $t-1$. Clearly, all generations $t^{\prime}$ with $t^{\prime} \leq t-2$ will be unaffected (they are dead already at $t$ ). From Proposition 2 all generations $t^{\prime}$ with $t^{\prime} \geq t$ will suffer from the introduction of the draft, relative to the professional-army scenario. Generation $t-1$ will, however, welcome the introduction of the draft since it will save the taxes it would, with a professional army, have had to pay during the second period of its working age. Its utility therefore is:

$$
V_{t-1}=-c\left(e^{p}\right)+\left(1-\tau^{p}\right) w\left(e^{p}\right)(1-\alpha)+w\left(e^{p}\right) /(1+r)>V^{p} .
$$

Hence, introducing the draft is beneficial to those who are old in the period of introduction but harms all future generations.

\subsection{Abolishing the draft}

Suppose now that prior to some date $t$ the economy was running a conscription system but that the government announces plans to switch to a professional army effectively by date $t$. Again assume that this policy change could not be anticipated prior to period $t$. Can such a move be arranged in a Pareto-improving way?

Introducing a professional army requires (additional) tax revenues. A Pareto-improving transition requires that generation $t-1$ (who has already delivered its military service under the draft system) must not be harmed 
by the new taxes. Hence, the taxes due in $t$ can only be levied on the then young generation $t$.

The necessary tax rate $\tau_{t}^{a}$ to finance abolition of the draft in period $t$ emerges from the budget constraint:

$$
\tau_{t}^{a} \cdot(1-\alpha) w\left(e_{t}\right)=\bar{m}
$$

where $(1-\alpha)$ is the working time of generation $t$ in period $t$. In period $t+1$, this generation will not pay any taxes. Hence, generation $t$ 's life-time income amounts to

$$
w\left(e_{t}\right) \cdot\left[(1-\alpha)\left(1-\tau_{t}^{a}\right)+\frac{1}{1+r}\right] .
$$

The same applies to all future generations; we therefore omit time subscripts henceforth. Utility maximization then implies that effort $e^{a}$ is chosen such as to satisfy:

$$
-c^{\prime}\left(e^{a}\right)+w^{\prime}\left(e^{a}\right) \cdot\left[(1-\alpha)\left(1-\tau^{a}\right)+\frac{1}{1+r}\right]=0
$$

or, after plugging in the (time-invariant) tax rate $\tau^{a}$,

$$
-c^{\prime}\left(e^{a}\right)+w^{\prime}\left(e^{a}\right) \cdot\left[1-\alpha+\frac{1}{1+r}-\frac{\bar{m}}{w\left(e^{a}\right)}\right]=0 .
$$

From this we obtain

Proposition 3 For all levels of military output $\bar{m}$, provided through a volunteer army, the effort into human capital and, consequently, output and consumption are never larger if the taxes needed to finance the army are levied exclusively on the young generation rather than spread across all cohorts:

$$
e^{a} \leq e^{p}
$$

The inequality in (13) is strict whenever $r>0$. 
Proof: Denote the function on the RHS of (12) by $\psi(e)$. Observe that $\psi\left(e^{a}\right)=0$ and that $\psi$ is strictly decreasing around $e^{a}: \psi^{\prime}\left(e^{a}\right)<0 .{ }^{5}$ Evaluate $\psi$ for $e=e^{p}$ and replace $-c^{\prime}\left(e^{p}\right)$ from (8):

$$
\begin{aligned}
\psi\left(e^{p}\right) & =-c^{\prime}\left(e^{p}\right)+w^{\prime}\left(e^{p}\right) \cdot\left[1-\alpha+\frac{1}{1+r}-\frac{\bar{m}}{w\left(e^{p}\right)}\right] \\
& =w^{\prime}\left(e^{p}\right) \cdot \frac{\bar{m}}{w\left(e^{p}\right)} \cdot\left(\frac{\Gamma}{2-\alpha}-1\right) \leq 0=\psi\left(e^{a}\right)
\end{aligned}
$$

where the non-positive sign of $\psi\left(e^{p}\right)$ follows from (2). The sign will be strictly negative whenever $r>0$. We therefore have $e^{p} \geq e^{a}$ due to the local monotonicity of $\psi$; the inequality being strict in the presence of discounting.

As productivity increases in $e$ and the government always takes away the same absolute amount $\bar{m}$ of resources for the military, the assertions for output and consumption follow immediately.

To see the impact of discounting on this result, recall that we are comparing two scenarios: one where taxes are levied at the same rate over the full life-cycle, and one where taxes are due only in the first period of one's life. With a zero interest rate and perfect capital markets, the timing of taxes is irrelevant. With a positive interest rate, front-loading taxes entails a higher burden, even if the amount of taxes that the government raises at any point in time is identical. Lower after-tax return to education reduces private investment in education. As could be expected, this also involves a loss in utility. Specifically, we obtain the following analogue to Proposition 2:

Proposition 4 Suppose the economy runs a professional army. Then the maximally obtainable utility level for the steady-state generations is never larger if taxes are levied exclusively on the young generation rather than

\footnotetext{
${ }^{5}$ As $e^{a}$ is a utility-maximizing choice, this follows from the second-order condition.
} 
spread across all cohorts:

$$
V^{a} \leq V^{p}
$$

The inequality is strict whenever $r>0$.

Proof: The following (in-)equalities hold:

$$
\begin{aligned}
V^{p} & =-c\left(e^{p}\right)+\left(1-\tau^{p}\right) w\left(e^{p}\right) \Gamma \\
& \geq-c\left(e^{a}\right)+\left(1-\tau^{p}\right) w\left(e^{a}\right) \Gamma \\
& =-c\left(e^{a}\right)+w\left(e^{a}\right)\left(1-\alpha+\frac{1}{1+r}-\frac{\Gamma}{2-\alpha} \cdot \frac{\bar{m}}{w\left(e^{p}\right)}\right) \\
& \geq-c\left(e^{a}\right)+w\left(e^{a}\right)\left(1-\alpha+\frac{1}{1+r}-\frac{\bar{m}}{w\left(e^{p}\right)}\right) \\
& \geq-c\left(e^{a}\right)+w\left(e^{a}\right)\left(1-\alpha+\frac{1}{1+r}-\frac{\bar{m}}{w\left(e^{a}\right)}\right)=V^{a} .
\end{aligned}
$$

The second line follows by a revealed-preference argument, the third replaces the budget-balancing tax rate $\tau^{p}$ and expands terms, the fourth follows from (2), and the fifth from (13). The inequalities in the fourth and fifth lines will be strict whenever $r>0$.

Hence, abolishing the draft and replacing it by a professional army that is financed by taxes only on the young leads to a situation that is worse for the steady-state generations than if the draft had never been introduced. Levying the tax on the young is, however, the only way to prevent the generation that is old when the transition from draft to professional army is inaugurated from being harmed by the transition. From this, we can conclude that the welfare of the steady-state generations is lower once the draft is introduced and again abolished than if it had never been there in the first place.

In particular, this result does not change if we allow the use of government debt during a transition. To see this, assume that the government has 
access to credit markets, and faces the same interest rate as individuals. ${ }^{6}$ Suppose that the government aims to organize transition from the draft to a professional army so that the young generation at the time of transition would be as well off as the young generations in a steady-state without draft. This would, however, require the government to issue public debt to reduce the lifetime tax burden of the initial young generation. As long as the government used public debt to keep the current young generation at the level of the steady-state generations without draft, public debt would accumulate. Once the government started to redeem its debt, the then young generations would be left with a lower utility level than without public debt.

In essence, the impossibility to completely undo the effects of a onceintroduced draft system is due to the same mechanism as the impossibility to replace an inefficient pay-as-you-go pension scheme by a funded one: Like the introduction of a pay-as-you-go scheme, introducing a draft amounts to a "present" to the generation that is old at that moment. Such a gift may be revolved, but can never be accomplished such as to make everybody in the future equally well off as without the gift.

Although abolishing the draft never can re-establish the situation with a professional army, doing so is nevertheless advisable since it improves the situation relative to a perpetuation of a draft scheme. I.e., the steady-state levels both of utility and of the stock of human capital in an economy with a permanent draft are lower than if the draft were abolished and the fiscal burden for professionalization was entirely front-loaded on young generations:

\footnotetext{
${ }^{6}$ If the government could borrow at a lower interest rate, then it would be optimal for the government to borrow money to subsidize the first period wage and finance this by taxing the second period wage, independently of whether there is draft or professional army. Assuming that the government and individuals face the same interest rate excludes such free lunches.
} 
Proposition 5 Abolishing a draft system and replacing it with a professional army that is financed by taxes that are exclusively levied on the young leads to a Pareto-improvement. It also goes along with an increase in the human capital stock of the economy.

Proof: Calculate:

$$
\begin{aligned}
V^{a}-V^{d}= & -c\left(e^{a}\right)+c\left(e^{d}\right)+w\left(e^{a}\right)\left(\Gamma-\frac{\bar{m}}{w\left(e^{a}\right)}\right)-w\left(e^{d}\right)(\Gamma-\bar{m}) \\
= & {\left[-c\left(e^{a}\right)+w\left(e^{a}\right)\left(\Gamma-\frac{\bar{m}}{w\left(e^{a}\right)}\right)+c\left(e^{d}\right)-w\left(e^{d}\right)\left(\Gamma-\frac{\bar{m}}{w\left(e^{d}\right)}\right)\right] } \\
& +\left(w\left(e^{d}\right)-1\right) \cdot \bar{m} \\
> & 0 .
\end{aligned}
$$

The expression in square brackets in the second line is non-negative as $e^{a}$ maximizes $-c(e)+w(e)\left(\Gamma-\frac{\bar{m}}{w(e)}\right)$. The bracketed expression in the third line is positive since $w\left(e^{d}\right)>1$. Hence, $V^{a}>V^{d}$.

To show that human capital investment will be lower in an economy with a draft than in one with an abolished draft, we evaluate the function $\phi(e)$ from the proof of Proposition 1 at $e^{a}$ :

$$
\begin{aligned}
\phi\left(e^{a}\right) & =-c^{\prime}\left(e^{a}\right)+w^{\prime}\left(e^{a}\right) \cdot(\Gamma-\bar{m}) \\
& =w^{\prime}\left(e^{a}\right) \cdot\left[-\Gamma+\frac{\bar{m}}{w\left(e^{a}\right)}+\Gamma-\bar{m}\right] \\
& =-w^{\prime}\left(e^{a}\right) \cdot \bar{m} \cdot\left(1-\frac{1}{w\left(e^{a}\right)}\right)<0=\phi\left(e^{d}\right) .
\end{aligned}
$$

Hence, $e^{a}>e^{d}$ due to the strict monotonicity of $\phi(e)$.

Taking stock of the results we get:

$$
V^{p} \geq V^{a}>V^{d}
$$


where the first inequality is strict if $r>0$. Running a professional army, thus, is the best option society could choose. The second inequality implies that a draft is an inefficient way of transferring resources to the initially elderly generation. Should society choose to give the initially elderly a windfall gain at the expense of all future generations, it is less costly to do this by starting to levy age-dependent taxes. Should the mistake of introducing a draft system be committed, society will have to pay a price for that: either it continues with the draft system, lowering utility levels to $V^{d}$, or one generation has to face a double burden, first being subject to the draft and then be additionally taxed when the draft is abolished. Taxing the older generation in the transition period for a second time (the first burden imposed on them was their conscription while young) would set the economy on the non-draft time path and would deliver the corresponding high utility for all future generations, in exchange for lower utility for the transition generation. If the transition from the draft system to a volunteer army is organized such as not to impose additional harm on those who have already been hurt by the draft, the tax costs of abolishing the draft are fully loaded on young generations by imposing age-dependent taxes. This would involve steady-state utility that fall in between the levels of perpetual volunteer and conscription systems.

We analyzed the transition from an all-volunteer force to an army of conscripts or vice versa in a model with only two overlapping generations. Correspondingly, the economy switches from one steady state to the other within just one period. However, this should not be seen as a limitation for the validity of our findings: In a stable $n$-OLG model (where $n>2$ ), the transition would take at most $n-1$ periods - until the first generation affected by the policy change has perished. Transitional dynamics might be more complex then, but the effects and the generational incidence of 
switching in the recruiting regime would be qualitatively identical.

\section{Conclusion}

In this paper, we analyze efficiency and distributional implications of the military draft and other compulsory work services. A specific and, to our knowledge, novel aspect of our paper is its focus on the introduction and abolition of such schemes. We adopt a dynamic framework, taking into account that both the draft and levying wage taxes affect individual incentives to invest in education. The draft forces young people to work for the government, thus postponing their education and entry to the labor market, and shortening their remaining working career. Wage taxes reduce the after-tax return to education, thus also discouraging investment in education.

We show that even if the draft were not plagued by inefficient matches between people and jobs, the lack of specialization, or other static inefficiencies it would still be a worse solution for steady-state generations than levying wage taxes to acquire the same labor input in market wages. The initially older generation, however, gains from the introduction of the draft since it will save the taxes it would, with a professional army, have had to pay. All future generations would lose. Abolishing the draft allows to reduce welfare losses and can always be implemented in a Pareto-improving manner. However, the utility available to steady-state generations after a draft system has been abolished in a Pareto-improving manner still falls short of their utility if a draft system had not been introduced in the first place. The reason for this is that a Pareto-improving elimination of draft requires collecting taxes only from the young, so as not to levy a double burden on the elderly who have already been subject to the draft. 
The draft can be understood and (mis-)used as a device for intergenerational redistribution, as it one-sidedly levies parts of the costs for the provision of government services on the young generations. In ageing European societies that, due to pay-as-you-go financing of pensions and health care, already load the lion's share of the burden of demographic transitions on younger generations, draft systems acerbate the intergenerational imbalances. It may well be questioned whether - apart from being unnecessarily costly - compulsory military or social services pass any meaningful test for intergenerational fairness.

The specific intergenerational incidence may help to explain the political allure of military draft and its corollaries. In our model with two overlapping generations, the older cohort benefits from introducing the draft. Moreover, once a draft scheme is installed, its abolition would harm the older generation, at least if one reasonably assumes that levying age-specific taxes is not feasible. The gist of these observations easily extends to models with larger numbers of overlapping generations (which may possibly be of unequal sizes). Since age cohorts beyond the draft age typically outnumber younger cohorts at or below the draft age, both the introduction and the continuance of military draft garner widespread political support - in spite of their inefficiency.

\section{References}

Angrist, J.D. (1990). Lifetime Earnings and the Vietnam Era Draft Lottery: Evidence from Social Security Administration Records. American Economic Review 80: $313-335$.

BBC News (2004). Russian Army Off-duty Deaths Rise. BBC News 
World Edition, 17 November, 2004.

CIA (2004). Military Manpower - Military Age and Obligation. In: The World Fact Book. Online at http://www.odci.gov/cia/publications/ factbook/fields/2024.html.

dw-world.de (2004). Politicians Call for Compulsory Social Year. Online at http://www.dw-world.de/dw/article/0, 1564,1092164,00.html.

Fisher, A.C. (1969). The Cost of the Draft and the Cost of Ending the Draft. American Economic Review 59: 239 - 254.

Hansen, W.L. and Weisbrod, B.A. (1967). Economics of the Military Draft. Quarterly Journal of Economics 81: 395 - 421.

Harford, J.D. and Marcus, R.D. (1988). A General Equilibrium Model of the Volunteer Military. Southern Economic Journal 55: 472 - 484.

Imbens, G. and van der Klaauw, W. (1995). Evaluating the Cost of Conscription in The Netherlands. Journal of Business and Economic Statistics 13: $207-215$.

ILO (2001). Stopping Forced Labour. Geneva: International Labour Organization. Online at www.ilo.org/declaration.

Lau, M.I., Poutvaara, P. and Wagener, A. (2004). Dynamic Costs of the Draft. German Economic Review 5: 381 - 406. 
Lee, D.R. and McKenzie, R.B. (1992). Reexamination of the Relative Efficiency of the Draft and the All-Volunteer Army. Southern Economic Journal 59: $646-654$.

Mulligan, C. and Shleifer, A. (2005). Conscription as Regulation. Forthcoming in American Law and Economics Review.

Oi, W.Y. (1967). The Economic Cost of the Draft. American Economic Review (Papers and Proceedings) 57: $39-62$.

Sandler, T. and Hartley, K. (1995). The Economics of Defense. Cambridge: Cambridge University Press.

Warner, J.T. and Asch, B.J. (2000). The Record and Prospects of the AllVolunteer Military in the United States. Journal of Economic Perspectives 15: $169-192$. 